\title{
MANAGEMENT AND OUTCOME IN TIBIAL DYSPLASIA
}

\author{
R. C. PATTINSON, J.A. FIXSEN
}

From the Hospitals for Sick Children, London

\begin{abstract}
Tibial dysplasia is a rare congenital deformity which must be distinguished from the more common fibular dysplasia. We have reviewed 24 patients with 35 affected legs. The classification system of Kalamchi and Dawe (1985) was found to be preferable to that of Jones, Barnes and Lloyd-Roberts (1978) as a guide to prognosis and management. We discuss the outcome of surgical treatment, recommending selective amputation for most cases.
\end{abstract}

Tibial dysplasia is a rare congenital condition of unknown aetiology, producing severe talipes equinovarus, leg shortening and instability of the knee (Fig. 1). The tibia is absent or dysplastic but the fibula is intact. It must be distinguished from the much more common fibular dysplasia with a short tibia, which is associated with a valgus foot and knee, variable absence of the lateral rays of the foot and tarsal coalition.

Tibial dysplasia occurs in about one in a million live births, may be inherited, and is sometimes associated with medial duplication of hands and feet (Fig. 2). In 1978 , Jones et al proposed a classification based on the initial radiological findings (Fig. 3) as a guide to management. We have reviewed some of the patients in the original study and others seen since 1978.

\section{METHODS}

Classification. The classification of Jones et al (1978) (Fig. 3) comprised five radiological types of deformity. It is now apparent, however, that in type $1 \mathrm{~b}$ and in type 3 , the proximal tibia may be present, but initially unossified. The later classification of Kalamchi and Dawe (1985; Fig. 4) is of three types. This provides a better guide to management since type I is complete absence of the tibia (Jones la), type II implies the presence of the proximal tibia (Jones 1 b, 2 and 3), while type III (Jones type 4) has severe diastasis of the ankle. The initial radiograph may be misleading, but the presence of the proximal tibia may be inferred when there is a normal distal femoral epiphysis or ossification of the distal tibia.

We recommend the use of the Kalamchi and Dawe

R. C. Pattinson, FRACS, Honorary Senior Registrar

J. A. Fixsen, MChir, FRCS, Consultant Orthopaedic Surgeon

Hospitals for Sick Children, Great Ormond Street, London WCIN

3JH, England

Correspondence should be sent to Mr J. A. Fixsen.

(C) 1992 British Editorial Society of Bone and Joint Surgery 0301-620X/92/6460\$2.00

J Bone Joint Surg [Br] 1992: 74-B :893-6. classification, since it covers all the variations. This is important for avoiding through-knee amputation in type II cases, in which a knee with active extension can be predicted.

Management. Our current plan for management is as follows: type I (Fig. 5), through-knee disarticulation; type II (Fig. 6), tibiofibular fusion and disarticulation of the foot; and type III (Fig. 7) disarticulation of the foot.

We have attempted reconstruction of the knee by the use of the fibula as described by Brown (1965) only in type I patients when through-knee disarticulation was not acceptable to the parents, or in patients from countries where no adequate prosthetic service was

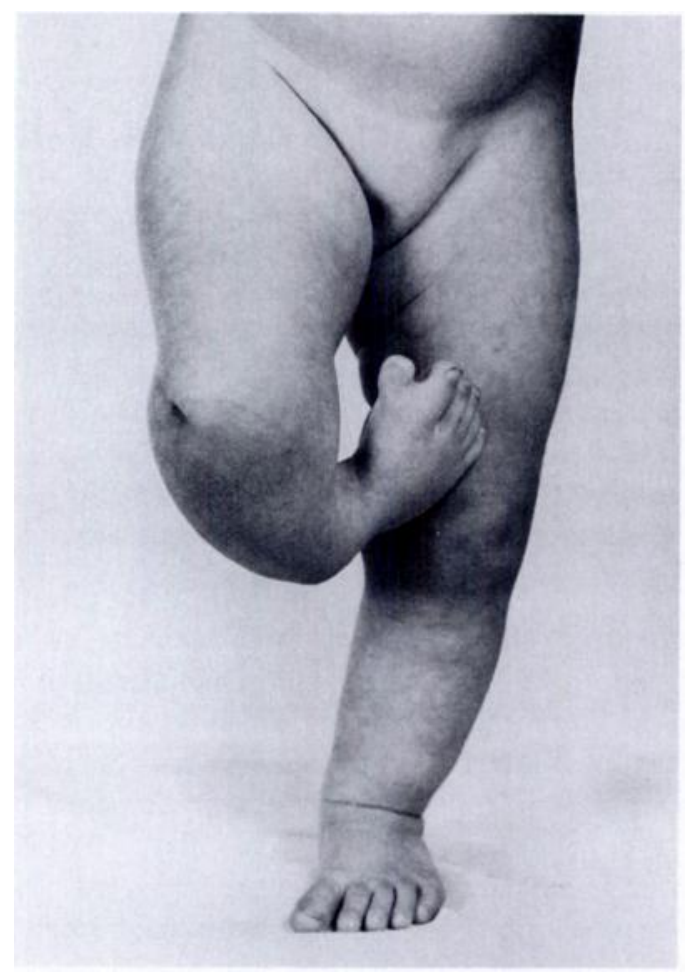

Fig. 1

Typical appearance of unilateral tibial dysplasia. 


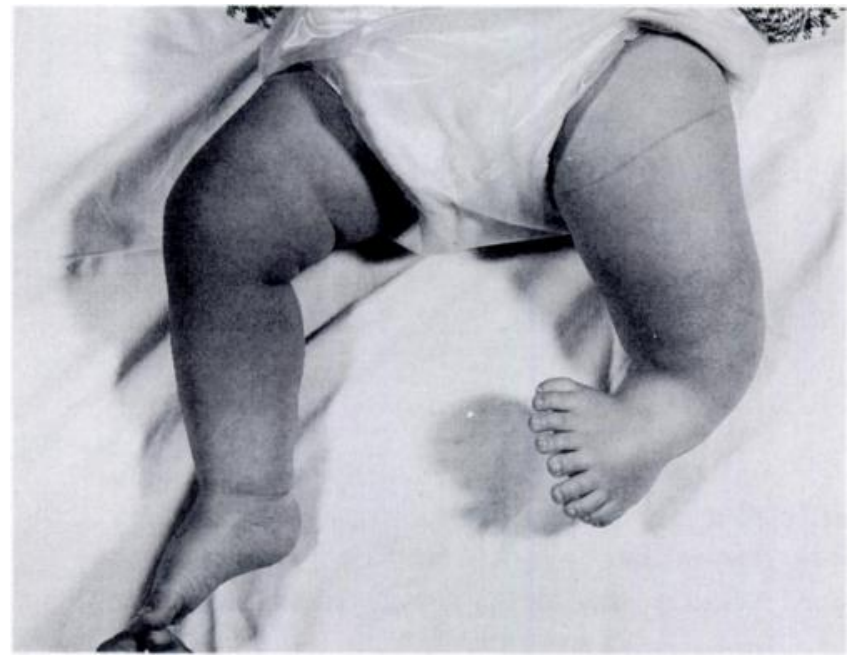

Fig. 2

A patient with unilateral diplopodia and tibial dysplasia.

available. Loder and Herring (1987) have reviewed this procedure and identified the problems as ligamentous instability, poor active range of movement and significant flexion contracture. These often result in the patient functioning as a through-knee amputee despite the retained fibula.

The timing and sequence of operations are important. Most patients have surgery when they are first able to stand, at between one and two years of age. They are then fitted with a pylon-type prosthesis (Fig. 8) which allows them to mobilise with children of their own age.

In patients with type II dysplasia in which the knee is preserved, the first operation is tibiofibular fusion (Fig. 9), retaining the foot to enhance control of the distal fibula during healing. At this operation the proximally migrated upper fibula may have to be excised; this also provides useful bone graft for the fusion site. Foot disarticulation is then performed as a second stage, six to eight weeks later, as soon as there is evidence of satisfactory fusion. Once the disarticulation stump has healed, a prosthesis can be fitted and mobilisation started.

\section{PATIENTS AND RESULTS}

Patients. Twenty-four patients with 35 affected legs have been seen at the Hospitals for Sick Children, Great Ormond Street since 1970. On the Kalamchi and Dawe classification, 17 legs were type I (bilateral in seven cases), 14 were type II (three bilateral) and four were type III (one bilateral). Of these, we were able to review nine patients with 12 affected legs at a special clinic. Their average age at follow-up was 12 years (5 to 19). Five were female and four were male.

The operations which had been performed were through-knee disarticulation for four type I legs, tibiofibular fusion with foot disarticulation for six type II, and foot disarticulation for two type III legs. The last two

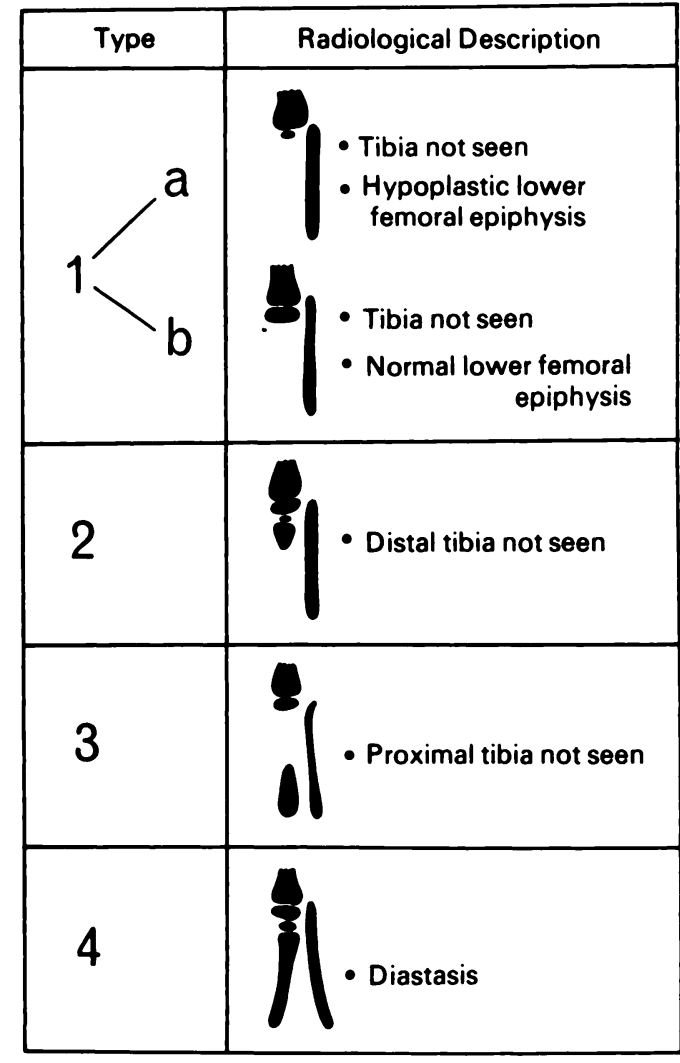

Fig. 3

The Jones, Barnes and Lloyd-Roberts (1978) classification of tibial dysplasia.

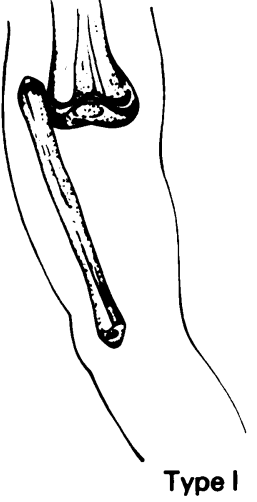

Type 1

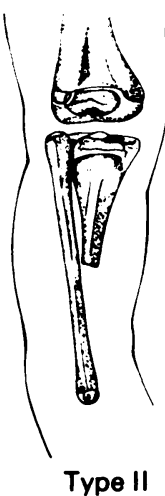

Fig. 4

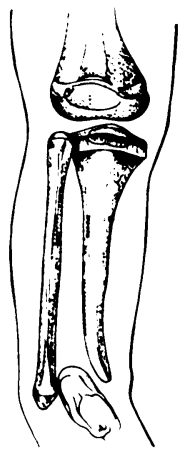

Type III
The Kalamchi and Dawe (1985) classification of tibial dysplasia.

patients had good function with below-knee prostheses (Fig. 10). The other seven had either thigh-lacer or total contact cuffs with hinged knee joints. Where the knee had been retained there was active extension, but hinge support was required for stability. All those old enough were able to drive cars with hand controls.

Associated anomalies. There were associated congenital anomalies in 19 of our 24 patients $(79 \%)$. These ranged from undescended testes to the caudal regression syndrome with absent vagina and anorectal anomalies, 


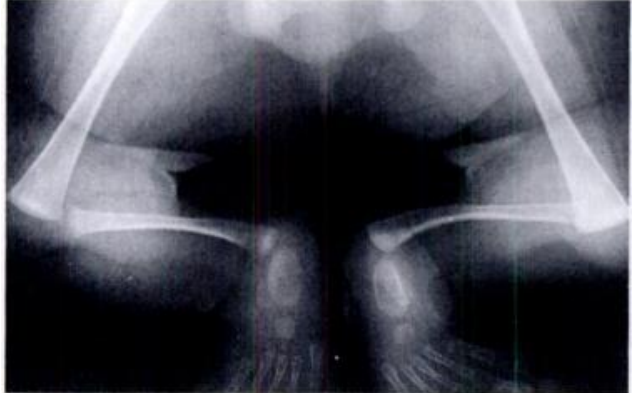

Fig. 5

Radiographs of the three grades of tibial dysplasia. Figure 5 - Bilateral type I. Figure 6 - Type II. Figure 7-Type III.

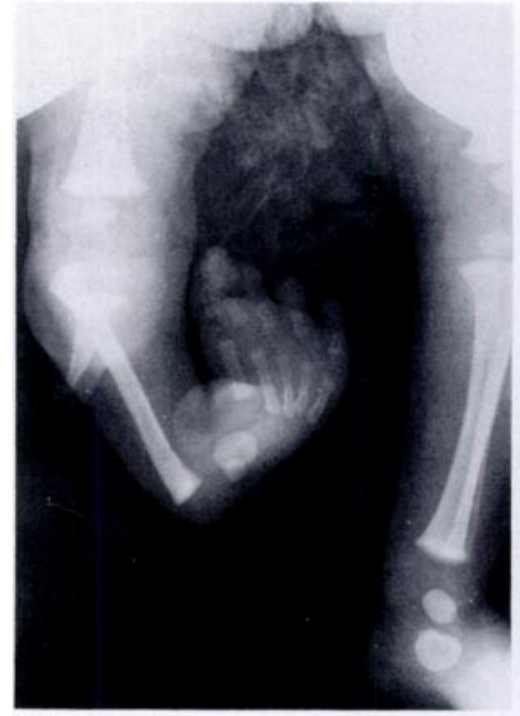

Fig. 6

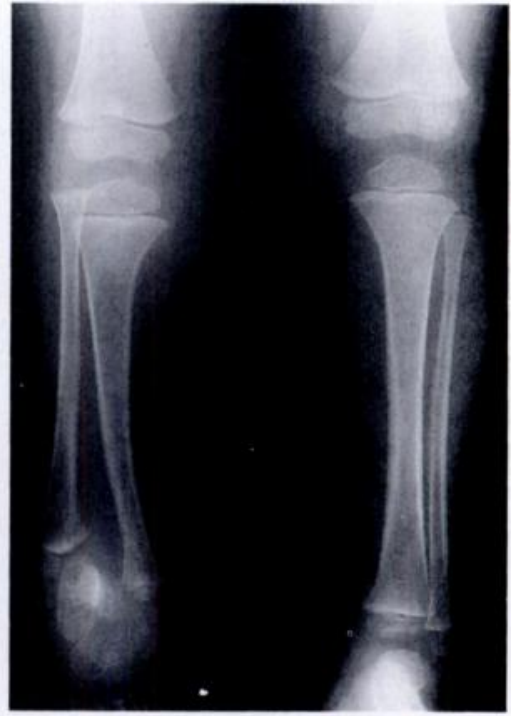

Fig. 7

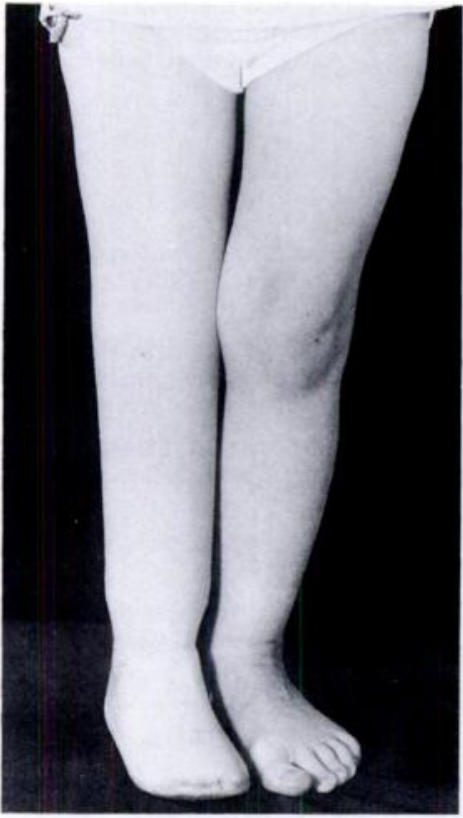

Fig. 8

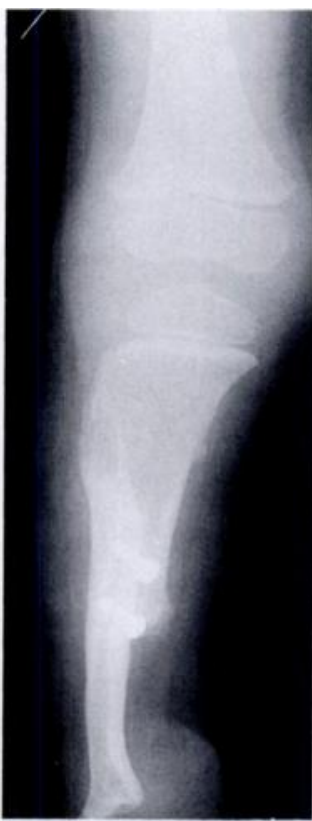

Fig. 9

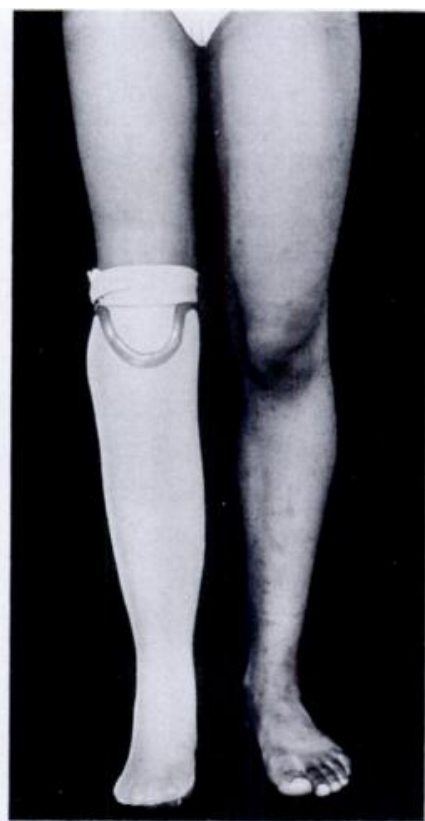

Fig. 10

Figure 8 - Solid pylon-type prosthesis. Figure 9 - Tibiofibular fusion for type II dysplasia. Figure 10 - Belowknee prosthesis.

which occurred in two patients. Thalidomide had been taken in pregnancy by the mothers of two of the patients. Inheritance. In one family, both father and son were affected. The father had had bilateral lower-leg amputations for congenital deformities, with complex polydactyly and syndactyly of both hands. His son had had bilateral through-knee disarticulations for type I dysplasia and multiple operations on his hands for bilateral complex syndactyly. The syndrome of polydactyly with absent tibia appears to be inherited as an autosomal dominant trait (Yugnovsky et al 1974).

In another family, neither parent was affected but three of the four siblings had tibial dysplasia: one had type I on one side and type III on the other, another had unilateral type II, and the third unilateral type III dysplasia.

\section{DISCUSSION}

Our experience of tibial dysplasia has led us to cease using the classification of Jones et al (1978) and to adopt that of Kalamchi and Dawe (1985), bearing in mind that the initial radiograph may be misleading because of delay in ossification of the proximal tibia. Confirmation 


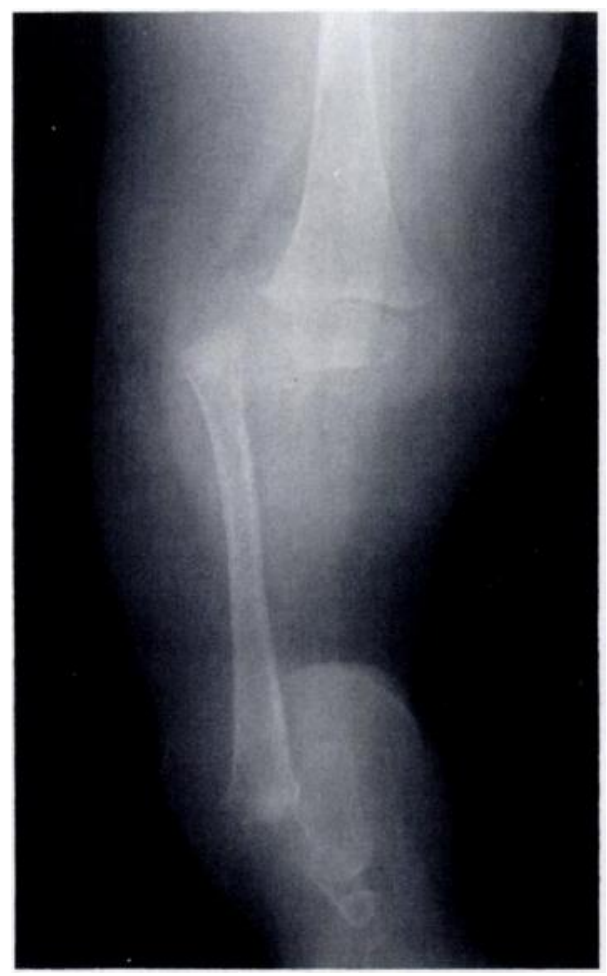

Fig. 11

Normal appearance of the distal femoral epiphysis with apparent absence of the tibia. The presence of an unossified proximal tibia may be inferred.

of the presence of the proximal tibia before ossification may be possible using MRI, but we have found that the appearance of a relatively normal distal femoral epiphysis on the initial radiograph also suggests that the proximal tibia is present (Fig. 11), and therefore that there is likely to be a functioning knee with an extensor apparatus. Such a knee should be preserved for use with a belowknee prosthesis.

In type II dysplasia the operation for tibiofibular fusion is not always straightforward; union may be difficult to obtain at the first attempt, and progressive deformity of the fibula may require corrective osteotomy. Where there is a complex foot and ankle problem, disarticulation of the foot still seems to be the best solution. This is relatively easy to accept for type I or type II deformities even allowing for modern leglengthening techniques. In type III deformity, however, in which the foot is not severely deformed, disarticulation can be difficult to accept both by the parents and the surgeon, but it is clear that retention of the foot is likely to require repeated surgery for recurrent deformity and leg lengthening (de Sanctis et al 1990). The possibility of associated hip dysplasia must be considered; this may require treatment.

Patients with tibial dysplasia have a severe congenital deformity and often require radical surgery. Despite this, they integrate well into the community, and often have excellent function and mobility in their prostheses.

The authors would like to thank the Medical Records Department and Medical Illustration Department of the Hospitals for Sick Children for their help and Miss A. J. Evans for typing the manuscript.

No benefits in any form have been received or will be received from a commercial party related directly or indirectly to the subject of this article.

\section{REFERENCES}

Brown FW. Construction of a knee joint in congenital total absence of the tibia (Paraxial Hemimelia Tibia): a preliminary report. $J$ Bone Joint Surg [ Am] 1965; 47-A :695-704.

de Sanctis N, Razzano E, Scognamiglio R, Rega AN. Tibial agenesis: a new rationale in management of type II : report of three cases with long-term follow-up. J Pediatr Orthop 1990; 10:198-201.

Jones D, Bames J, Lloyd-Roberts GC. Congenital aplasia and dysplasia of the tibia with intact fibula. J Bone Joint Surg [Br] 1978; 60B:31-9.

Kalamchi A, Dawe RV. Congenital deficiency of the tibia. J Bone Joint Surg $[\mathrm{Br}] 1985 ; 67-\mathrm{B}: 581-4$.

Loder RT, Herring JA. Fibular transfer for congenital absence of the tibia: a reassessment. J Pediatr Orthop 1987; 7:8-13.

Yugnovsky O, Ayala D, Vincitorio A, et al. A syndrome of polydactylysyndactyly and triphalangeal thumbs in three generations. Clin Genet 1974; 6:51-9. 